

\section{Transalkylation of Toluene with 1,2,4- Trimethylbenzene over Large Pore Zeolites}

Faisal M. Almulla ${ }^{a}$,Vladimir I. Zholobenko ${ }^{b}$, Patrick I. Hill ${ }^{a}$, Sarayute Chansai ${ }^{a}$ and Arthur A. Garforth $^{a}$

${ }^{\mathrm{a}}$ School of Chemical Engineering and Analytical Science, The University of Manchester, M13 9PL, UK, arthur.garforth@manchester.ac.uk

${ }^{\mathrm{b}}$ School of Chemical and Physical Sciences, Keele University, ST5 5BG, UK

KEYWORDS

Transalkylation, toluene, 1,2,4-trimethylbenzene, Beta, Y, Mordenite, ZSM-5

\section{ABSTRACT}

Using industrially relevant operating parameters, the transalkylation of 1,2,4Trimethylbenzene (TMB) with toluene was studied. The effect of acidity and structure, increased reaction pressure and very low levels of Pt impregnation have been investigated over both H-form and Pt-loaded zeolites: Beta, MOR, and Y. A fixed bed reactor was used at WHSV of $5 \mathrm{~h}^{-1}, 400{ }^{\circ} \mathrm{C}$ and a 50:50 wt. \% Toluene:TMB ratio with the order of activity after $50 \mathrm{~h}$ TOS of $\mathrm{Y}>$ Beta $>>$ MOR at 1 bar. At elevated pressure $(10 \mathrm{bar})$, all catalysts showed better performance with significant improvement in MOR as pore blockage reduced and the order of activity was Beta $>$ MOR $>$ Y. Incorporation of Pt (0.08wt. \%) further improved the activity of all catalysts with the highest conversion after $50 \mathrm{~h}$ TOS over Beta (62 wt. \%) where Beta and MOR yielded similar levels of xylenes (40 wt. \%). All catalysts were further optimized for activity whilst maintaining the desired stability and highest xylenes yield. 


\section{Introduction}

The use of aromatics to produce petrochemicals is incentivised by the recent reduction of total aromatics in motor fuels. Benzene, toluene, and xylene (BTX) are the three main raw materials used to produce aromatic derivatives. Xylene isomers $(o-, m-$, and $p$-), with their continuous growing global demand over benzene, ${ }^{1}$ are the starting components for the production of different important polymers such as synthetic fibres, unsaturated polyester resins, and phthalate plasticizers.

Owing to the low market demand for toluene, several processes were developed such as hydrodealkylation, ${ }^{2}$ toluene disproportionation ${ }^{3,4}$ and transalkylation ${ }^{5}$ to convert the surplus toluene into more valued products e.g. benzene and xylene. Transalkylation of toluene with heavy aromatics $\left(\mathrm{C}_{9}\right)$ is a promising reaction aiming to produce xylenes in Figure 1. Other possible side reactions include disproportionation of toluene and TMB; xylene and TMB isomerization; and, dealkylation of $\mathrm{TMB}$ and toluene to produce toluene and benzene respectively with light gases. ${ }^{6}$

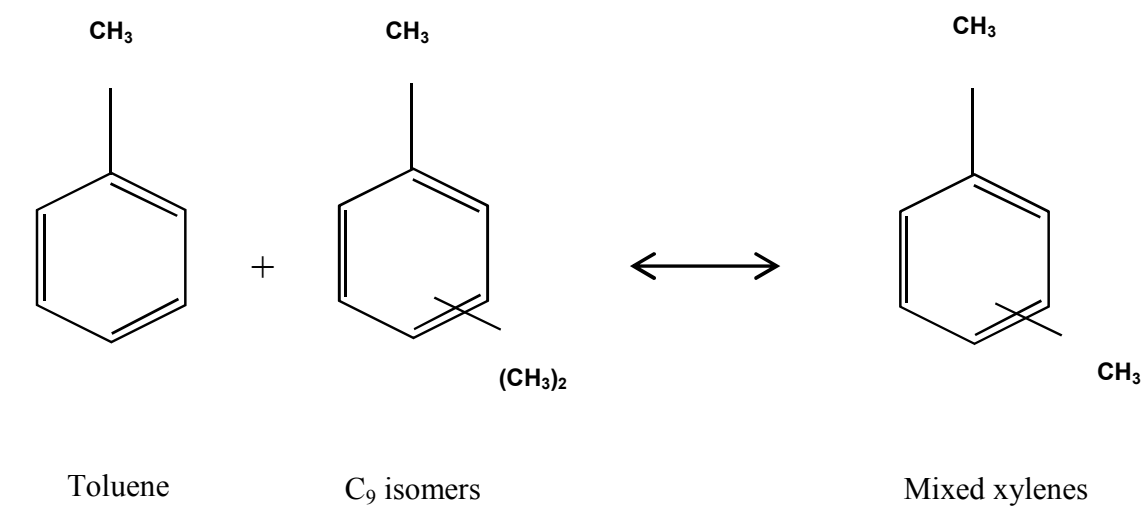

Figure 1: Transalkylation reaction of toluene with 1,2,4-trimethylbenzene.

A number of commercial transalkylation processes have been developed such Xylene-Plus process developed by ARCO-IFP, ${ }^{7}$ Tatoray $^{\mathrm{TM}}$ process developed by UOP, ${ }^{8}$ and TransPlus process developed by Mobil-CPC ${ }^{9}$ with key operating parameters listed in Table 1. Research on 
transalkylation has been carried out using various types of zeolites, including both medium pore zeolites, such as ZSM-5, ${ }^{10} \mathrm{NU}-87,{ }^{11}$ and MCM-22, ${ }^{12}$ and large pore zeolites, such as zeolite $\mathrm{Y},{ }^{13}$ Beta, ${ }^{14}$ mordenite, ${ }^{15}$ SAPO-5, ${ }^{16}$ and ZSM-12. ${ }^{17}$ This research demonstrated that zeolite based catalysts have unique properties promoting their use in aromatic transformations. The concentration of Brønsted and Lewis acid sites has been shown to directly influence the reaction pathway with Lewis acid sites promoting toluene/TMB disproportionation and Brønsted acid sites promoting transalkylation. ${ }^{18}$ Matsuda et al. ${ }^{19}$ have also reported that TMB isomerization could occur predominantly over Brønsted acid sites.

Table 1: Overview on key operating conditions used in commercial transalkylation processes. ${ }^{7-9}$

\begin{tabular}{llll}
\hline & \multicolumn{3}{c}{ Process name } \\
\cline { 2 - 4 } & Tatoray & Xylene-plus & TransPlus \\
\hline Reactor type & Fixed bed & Moving bed & Fixed bed \\
Temperature $\left({ }^{\circ} \mathrm{C}\right)$ & $380-500$ & $454-538$ & $385-500$ \\
Pressure $($ bar $)$ & $30-40$ & $1.1-1.3$ & $20-30$ \\
$\mathbf{H}_{\mathbf{2}} / \mathbf{H C}$ ratio $(\mathrm{mol} \%)$ & $4-6$ & None & $1-3$ \\
WHSV $\left(\mathrm{h}^{-1}\right)$ & $1.5-2.2$ & $0.7-1.7$ & $2.5-3.5$ \\
\hline
\end{tabular}

Catalyst lifetime, which is primarily affected by its deactivation, is a major concern in the transalkylation process where the conversion of $\mathrm{C}_{7}$ and $\mathrm{C}_{9}$ aromatic molecules is influenced by the zeolite pore structure. Fan and Wang et al. highlighted the importance of bulky dimethyl diphenylmethane intermediates (DPMs) in the activity of medium and large pore zeolites. ${ }^{20}$

As shown in Table 2, the three trimethylbenzene (TMB) isomers (1,3,5-, 1,2,4-, 1,2,3-) account for 45 wt. $\%$ of $\mathrm{C}_{9}{ }^{21}$ with $1,2,4-\mathrm{TMB}$ being typically $60-65 \%$ of total $\mathrm{TMBs}^{22}$ In commercial heavy reformate, the typical amount of $1,2,4-\mathrm{TMB}$ is $39 \%$ and hence $1,2,4-\mathrm{TMB}$ can be considered as a representative model compound of $\mathrm{C}_{9}$ aromatics to be investigated in the transalkylation tests. 
The addition of low levels of metals introduces bi-functionality, improving catalyst stability and xylene product yield, dependent on the conditions used, whilst minimising the increase in catalyst cost. Meshram et al. ${ }^{23}$ impregnated Ni (0.5 wt. \%) into ZSM-5 based catalyst to reduce the catalyst aging. Adding $\mathrm{Ni}(2.4 \text { wt. } \%)^{24}$ and $\mathrm{Pd}(0.43 \mathrm{wt} . \%)^{25}$ onto mordenite based zeolite catalysts was shown to reduce coke formation and improve stability. Another study on mordenite incorporated Pt (0.06 and 5 wt. \% $)^{17}$ and only the higher level of Pt increased toluene conversion in the transalkylation of toluene with $1,3,5-\mathrm{TMB}$. Chao et al. ${ }^{26}$ used pre-coking treatments on PtZSM-12 (0.02 wt. \%) to help stabilize feed conversion and reduce hydrogenated impurities in the benzene produced

Table 2: Typical compositions (wt. \%) of the commercial heavy reformate and $\mathrm{C}_{9}$ aromatics.

\begin{tabular}{lcc}
\hline & Heavy Reformate $^{27}$ & $\mathrm{C}_{9}$ aromatics $^{28}$ \\
\hline Iso-propyl benzene & 1.7 & 1.0 \\
n-propyl benzene & 4.3 & 3.0 \\
1-methyl 2-ethylbenzene & 6.5 & 8.0 \\
1-methyl 3-ethylbenzene & 18.5 & 19.0 \\
1-methyl 4-ethylbenzene & 9.1 & 11.0 \\
1,2,3-trimethylbenzene & 6.6 & 10.0 \\
1,2,4-trimethylbenzene & 39.0 & 36.0 \\
1,3,5-trimethylbenzene & 10.1 & 12.0 \\
n-butyl benzene & Total $C_{9}$ aromatics: 95.9 & - \\
1,4-diethylbenzene & 0.5 & - \\
1,3-diethylbenzene & 0.8 & - \\
1,3-dimethyl, 5-ethyl benzene & 0.4 & - \\
1,4-dimethyl, 2-ethyl benzene & 0.8 & - \\
Others $\mathrm{C}_{10} \mathrm{~S}$ & 0.4 & - \\
& 1.2 & \\
\hline
\end{tabular}

In this work, the role of large-pore zeolites in the transalkylation of toluene with $1,2,4-\mathrm{TMB}$ aiming to produce xylenes using industrially relevant operating parameters has been investigated. The study considers the effects of the zeolite structure, the reaction pressure, and the incorporation of low platinum levels. In addition, the effect of time-on-stream on deactivation behaviour has also been examined. 


\section{Experimental Procedure}

\subsection{Materials}

Zeolite Beta, Y and mordenite (MOR) were obtained from Zeolyst International, and the main characteristics of the large pore catalysts are shown in Table 3. The feed was an equal weight mixture of toluene (Fluka $>99.7 \%$ ) and 1,2,4-TMB (Sigma-Aldrich $>98.0 \%$ ), both chemicals were used as received and the space velocity was based on the total feed flow rate. Hydrogen (99.99 wt. \% purity, BOC) was used to feed the reactor and tetra-ammine platinum (II) chloride $\left(\mathrm{Pt}\left(\mathrm{NH}_{3}\right)_{4} \mathrm{Cl}_{2}\right)$ (Sigma-Aldrich, 98 wt. \% purity) used for Pt loading.

Table 3: Characteristics of zeolites used in the transalkylation tests.

\begin{tabular}{cccccc}
\hline Zeolite & $\begin{array}{c}\text { Channel } \\
\text { Dimension }\end{array}$ & $\begin{array}{c}\text { Pore Entrance } \\
(\mathrm{T} \text { atoms })\end{array}$ & $\begin{array}{c}\text { Channel Diameter } \\
(\mathrm{nm})\end{array}$ & $\begin{array}{c}\text { Surface } \text { area }^{1} \\
\left(\mathrm{~m}^{2} / \mathrm{g}\right)\end{array}$ & $\mathrm{Si}^{-\mathrm{Al}^{1}}$ \\
\hline MOR & 1D & $12 \mathrm{~T}$ & $0.65 \times 0.70$ & 500 & 10.0 \\
Y & 3D & $12 \mathrm{~T}$ & $0.74 \times 0.74$ & 730 & 6.0 \\
Beta & 3D & $12 \mathrm{~T}$ & $0.65 \times 0.67$ & 680 & 12.5 \\
\hline
\end{tabular}

\footnotetext{
${ }^{1}$ As quantified by manufacturer.
}

\subsection{Catalyst preparation}

Ammonium exchanged zeolites were calcined in a three zone tubular furnace at $500{ }^{\circ} \mathrm{C}$ for 16 $\mathrm{h}$ at a ramping rate of $1.5{ }^{\circ} \mathrm{C} \mathrm{min}^{-1}$ under flowing air $\left(30 \mathrm{ml} \mathrm{min}^{-1}\right)$. After calcination, the zeolite was mixed with the appropriate platinum salt $\mathrm{Pt}\left(\mathrm{NH}_{3}\right)_{4} \mathrm{Cl}_{2}$ in deionized water $(1 \mathrm{~g}: 10 \mathrm{~mL}$ zeolite:solution ratio) and stirred for $24 \mathrm{~h}$ at an average temperature of $65^{\circ} \mathrm{C}$. The samples were then dried at $110^{\circ} \mathrm{C}$ for $12 \mathrm{~h}$. An additional calcination step $\left(500^{\circ} \mathrm{C}\right)$ for $8 \mathrm{~h}$ was carried out insitu for the Pt-loaded zeolites. Then, the temperature was reduced to $450{ }^{\circ} \mathrm{C}$ and air was switched to $\mathrm{H}_{2}\left(70 \mathrm{ml} \mathrm{min}^{-1}\right)$ and held for $16 \mathrm{~h}$ to reduce the platinum in the zeolite.

\subsection{Catalyst Characterization}

The catalysts were characterised by X-ray diffraction (XRD, Rigaku-Miniflex), scanning electron microscopy (FEI Quanta 200) and transmission electron microscopy (FEI Technai F30). Coke deposition on the spent catalysts was analysed using thermogravimetric analysis (Q5000- 
IR, TA Instruments). The amount of $\mathrm{Si}, \mathrm{Al}$, and $\mathrm{Pt}$ in zeolite was determined by HF digestion followed by inductively coupled plasma optical emission spectroscopy (ICP-OES-MEDAC LTD). BET surface area was measured using a Micromeritics Gemini 2365 surface area analyser and the Pt particle size, dispersion and surface area were determined using a Quantachrome ChemBET Pulsar TPR/TPD analyser. Pt containing zeolites were reduced at $450{ }^{\circ} \mathrm{C}$ for $1 \mathrm{~h}$ in flowing $\mathrm{H}_{2}$ at $40 \mathrm{ml} / \mathrm{min}$; then the adsorption of $\mathrm{CO}$ carried out at $-50{ }^{\circ} \mathrm{C}$ using pulses of $1 \% \mathrm{CO}$ in Argon (BOC). In addition, the distribution and size of the platinum within the catalyst was observed using high-angle annular dark-field (HADF) imaging on a FEI F30 transmission electron microscope (TEM) operating at $300 \mathrm{kV}$ in STEM mode. Characterisation of the acidic $\mathrm{OH}$ groups (Brønsted acid sites) and Lewis acid sites in zeolites was carried out using pyridine (Py) adsorption and transmittance FTIR measurements in the 4000-1200 $\mathrm{cm}^{-1}$ spectral range at 4 $\mathrm{cm}^{-1}$ resolution using a Thermo iS10 spectrometer. After the zeolite was dehydrated at $450{ }^{\circ} \mathrm{C}$, the temperature was reduced to $150^{\circ} \mathrm{C}$ and Py was admitted into the vacuum transmittance cell in a stepwise manner until no changes in the spectra were observed. The saturated sample was then evacuated for $10 \mathrm{~min}$ at $150{ }^{\circ} \mathrm{C}$ to remove physically adsorbed Py and the FTIR spectrum was collected.

\subsection{Catalytic Testing}

The catalyst powder $(1 \mathrm{~g})$ was pressed, crushed and sieved to $250-425 \mu \mathrm{m}$ and then placed in a stainless steel down-flow fixed bed reactor $(530 \mathrm{~mm}$ length $\times 10 \mathrm{~mm} \mathrm{ID})$ with a type $\mathrm{K}$ thermocouple to measure the catalyst reaction temperature. The liquid feed was introduced to the reactor using a Jasco HPLC pump PU-980, while air and hydrogen flows were controlled using gas mass flow controllers (Brooks 5880). The liquid and $\mathrm{H}_{2}$ feeds were premixed prior to entering the reactor and a back pressure regulator controlled the system pressure. 
The catalytic activity for all samples was studied at $400{ }^{\circ} \mathrm{C}$, a molar $\mathrm{H}_{2} / \mathrm{HC}$ ratio of 4 , a WHSV value of $5 \mathrm{~h}^{-1}$ and the pressure varied between 1 and 10 bar. The overall conversion $(1,2,4-\mathrm{TMB}+$ toluene $)$ was calculated using equation 1 , where $\mathrm{m}_{\mathrm{Tol}}$ and $\mathrm{m}_{\mathrm{TMB}}$ are the weight of toluene and 1,2,4-TMB, respectively.

$$
\mathrm{X}_{\mathrm{wt} . \%}=\frac{\left(\mathrm{m}_{\mathrm{Tol}}+\mathrm{m}_{\mathrm{TMB}}\right) \text { in }-\left(\mathrm{m}_{\mathrm{Tol}}+\mathrm{m}_{\mathrm{TMB}}\right) \text { out }}{\left(\mathrm{m}_{\mathrm{Tol}}+\mathrm{m}_{\mathrm{TMB}}\right) \text { in }} \times 100
$$

\subsection{Feed and Product Analysis}

The feed and product samples were analysed using a Varian 3400 Gas Chromatograph fitted with a Stabilwax Capillary Column $(30 \mathrm{~m} \times 0.32 \mathrm{~mm}$ i.d. $\times 1.0 \mu \mathrm{m}$ film thickness $)$ using a flame ionization detector (FID).

\section{Results and Discussion}

\subsection{Characterization Results}

\subsubsection{Elemental Analysis}

The $\mathrm{Si}$ and $\mathrm{Al}$ composition of tested catalysts is shown in Table 4 where the error was $\pm 0.1 \%$, and the $\mathrm{Si} / \mathrm{Al}$ ratios were found to be in good agreement with those quoted by the manufacturer. The platinum loading was found to be within 5\% of the targeted amount allowing for measurement error (typically $\pm 10 \mathrm{ppm})$.

\subsubsection{BET surface area \\ The surface area of the catalysts is presented in Table 4 and decreased in the order of Y $>$ Beta $>$ MOR. A small decrease in the surface area was observed when Pt was incorporated, however, as the Pt content increased very little change was observed (further data shown in the supporting information).}


Table 4: Characterization results of the zeolites/Pt-zeolites used in this study.

\begin{tabular}{|c|c|c|c|c|c|c|}
\hline Zeolite & Element & Results & Units & $\mathbf{S i} / \mathbf{A l}$ & $\begin{array}{c}\text { BET surface area } \\
\left(\mathrm{m}^{2} / \mathrm{g}\right)\end{array}$ & $\begin{array}{l}\text { Pore Volume } \\
\qquad\left(\mathrm{cm}^{3} / \mathrm{g}\right)\end{array}$ \\
\hline & $\mathrm{Al}$ & 2.85 & $\%$ & & & \\
\hline \multirow[t]{3}{*}{ MOR } & $\mathrm{Si}$ & 34.1 & $\%$ & 12.0 & 459 & 0.23 \\
\hline & $\mathrm{Pt}$ & - & ppm & & & \\
\hline & $\mathrm{Al}$ & 5.08 & $\%$ & & & \\
\hline \multirow[t]{3}{*}{$\mathbf{Y}$} & $\mathrm{Si}$ & 34.47 & $\%$ & 6.8 & 571 & 0.25 \\
\hline & $\mathrm{Pt}$ & - & ppm & & & \\
\hline & $\mathrm{Al}$ & 2.88 & $\%$ & & & \\
\hline \multirow[t]{3}{*}{ Beta } & $\mathrm{Si}$ & 36.51 & $\%$ & 12.7 & 531 & 0.18 \\
\hline & $\mathrm{Pt}$ & - & ppm & & & \\
\hline & $\mathrm{Al}$ & 3.41 & $\%$ & & & \\
\hline \multirow[t]{3}{*}{ Pt-MOR-800 } & $\mathrm{Si}$ & 40.77 & $\%$ & 12.0 & 382 & 0.22 \\
\hline & $\mathrm{Pt}$ & 843 & ppm & & & \\
\hline & $\mathrm{Al}$ & 5.05 & $\%$ & & & \\
\hline \multirow[t]{3}{*}{ Pt-Y-800 } & $\mathrm{Si}$ & 34.61 & $\%$ & 6.9 & 542 & 0.24 \\
\hline & $\mathrm{Pt}$ & 873 & ppm & & & \\
\hline & $\mathrm{Al}$ & 2.89 & $\%$ & & & \\
\hline \multirow[t]{3}{*}{ Pt-Beta-200 } & $\mathrm{Si}$ & 36.45 & $\%$ & 12.6 & 437 & 0.13 \\
\hline & $\mathrm{Pt}$ & 220 & ppm & & & \\
\hline & $\mathrm{Al}$ & 2.86 & $\%$ & & & \\
\hline \multirow[t]{3}{*}{ Pt-Beta-400 } & $\mathrm{Si}$ & 36.22 & $\%$ & 12.7 & 417 & 0.12 \\
\hline & $\mathrm{Pt}$ & 412 & ppm & & & \\
\hline & $\mathrm{Al}$ & 2.89 & $\%$ & & & \\
\hline \multirow[t]{2}{*}{ Pt-Beta-800 } & $\mathrm{Si}$ & 37.66 & $\%$ & 13.0 & 457 & 0.13 \\
\hline & $\mathrm{Pt}$ & 829 & ppm & & & \\
\hline
\end{tabular}

\subsubsection{Py-FTIR}

The acid sites were investigated using the intensity of the Py- $\mathrm{H}^{+}$and Py-L peaks at $\sim 1455$ and $1545 \mathrm{~cm}^{-1}$ to compare the effective acidity of the tested catalysts (Py-FTIR spectra are available in the supporting information). The highest Brønsted concentration was observed for MOR and therefore should be expected to favour transalkylation, whereas Y and Beta with higher Lewis acidity and lower Brønsted might show increased disproportionation (Table 5). 
Both Beta and Y had similar Brønsted and Lewis concentrations and therefore the effect of structure on the reaction pathway should be observable.

Table 5: Acid site concentrations for the studied zeolites determined by Py-FTIR adsorption.

\begin{tabular}{cccc}
\hline Zeolite & \multicolumn{3}{c}{ Py-FTIR (mmol/g) } \\
\hline \\
MOR & Brønsted (B) & Lewis (L) & B/L \\
Y & 1.07 & 0.19 & 5.62 \\
Beta & 0.37 & 0.56 & 0.66 \\
\end{tabular}

\subsubsection{X-ray Diffraction and Scanning Electron Microscope (SEM)}

The XRD patterns of the calcined catalysts showed good crystallinity and purity (Figure 2) and SEM analysis showed the varying particle sizes of the different zeolites (Figure 3). Typically, the aggregate size for Beta was about $0.2-0.4 \mu \mathrm{m}, 0.25-1.0 \mu \mathrm{m}$ for MOR and $0.5-$ $1.0 \mu \mathrm{m}$ for $\mathrm{Y}$ with no observable amorphous material.

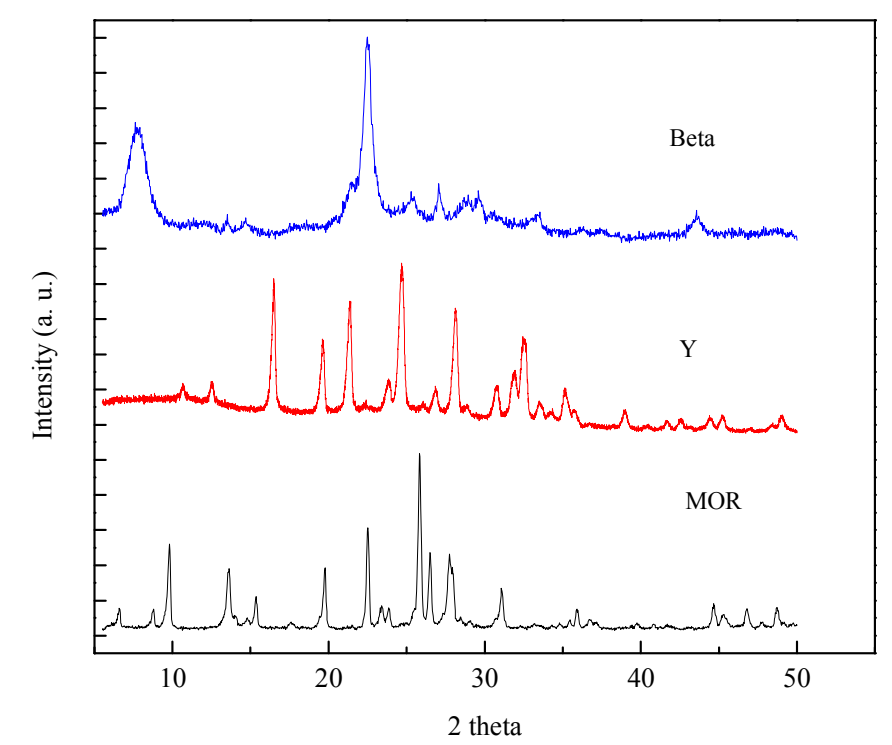

Figure 2: X-ray diffraction patterns for the catalysts used in this study. 


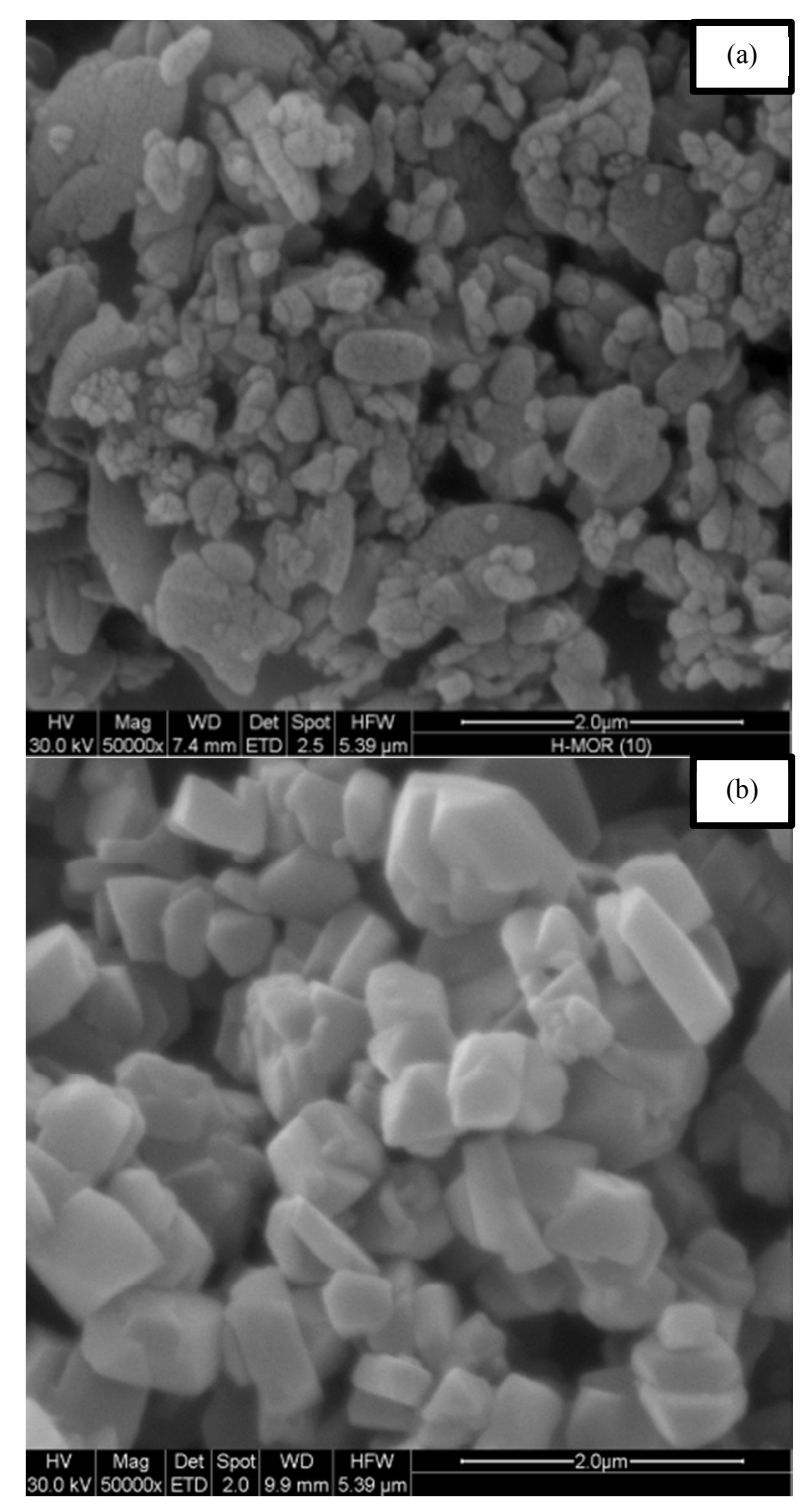

1
2
3
4
5
6
7
8
9
10
11
12
13
14
15
16
17
18
19
20
21
22
23
24
25
26
27
28
29
30
31
32
33
34
35
36
37
38
39
40
41
42
43
44
45
46
47
48
49
50
51
52
53
54
55
56
57
58
60

2 


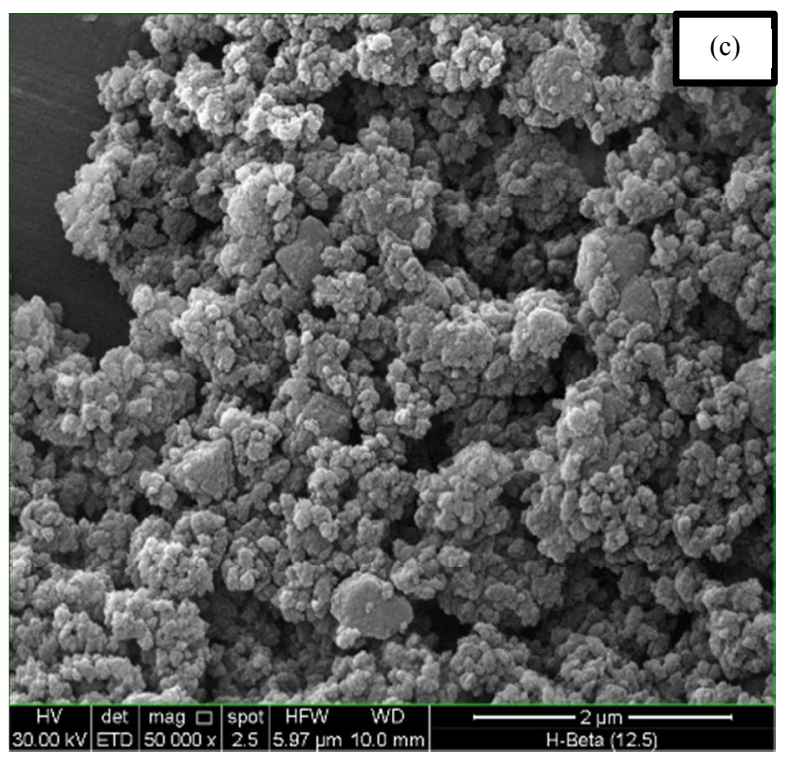

Figure 3: SEM images of zeolites MOR (a), Y (b), and Beta (c).

\subsubsection{Chemisorption}

The chemisorption results for Pt-Beta showed good Pt dispersion of 71 and $82 \%$ for 400 and $800 \mathrm{ppm}$, respectively, with an average particle size of $1.3 \mathrm{~nm}$ (Table 6).

Table 6: Chemisorption Results for Pt-Beta.

\begin{tabular}{cccc}
\hline Catalyst & Metallic surface area $\left(\mathrm{m}^{2} / \mathbf{g}\right)$ & Metallic dispersion (\%) & Avg. particle size (nm) \\
\hline Pt-Beta-400 & 0.07 & 71 & 1.4 \\
Pt-Beta-800 & 0.16 & 82 & 1.2 \\
\hline
\end{tabular}

\subsubsection{Transmission Electron Microscopy (TEM)}

TEM bright field images of Pt-Beta800 catalyst (Figure 4) showed the average Pt particles to be in agreement with the $\mathrm{CO}$ adsorption (shown as white dots located within the zeolite support) with the average size of each Pt particle was found to be between $1.0-1.5 \mathrm{~nm}$. With the dispersed Pt cluster size typically of $1.3 \mathrm{~nm}$ and since the intra crystalline pore diameter of Beta is $0.67 \mathrm{~nm}$, the platinum must be predominantly located on the external crystalline surfaces of the zeolite. The location and level of dispersion observed was in line with a previous study where comparison of metal loading methods demonstrated much higher dispersion obtained when using impregnation as opposed to ion exchange. ${ }^{29}$ 

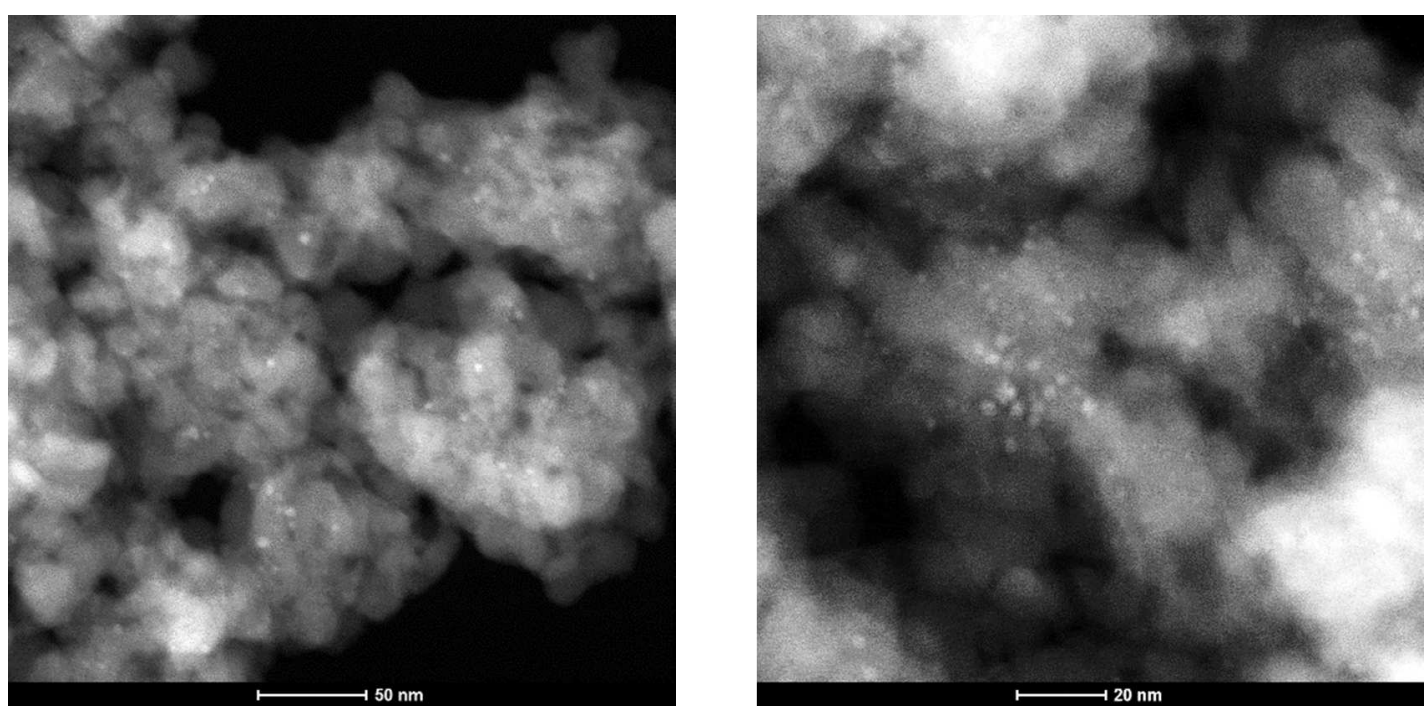

Figure 4: TEM (HADF) images showing Pt aggregates for Pt-Beta-800.

\subsection{The effect of pressure on the catalytic activity of large pore zeolites}

Conversion and xylenes yield were compared at 1 and 10 bar over MOR, Y, and Beta (Figure

5). The deactivation was investigated with time on stream, and as expected, at atmospheric pressure the conversion of MOR dropped rapidly and after $50 \mathrm{~h}$ TOS was less than 2 wt. \% with $<1$ wt. \% xylene yield. However, zeolites with a three-dimensional framework are less sensitive to pore blockage from larger aromatics and coke precursors and hence showed less deactivation, resulting in conversion over Beta and $\mathrm{Y}$ reducing to 24 and 29 wt. \%, respectively after $50 \mathrm{~h}$ TOS (Figure 5a). The yield of xylenes showed a similar trend to conversion with typical values of 7 wt. \% over Beta and 11 wt. \% over Y after 50 h TOS (Figure $5 b$ ).

The three catalysts showed different deactivation behaviour on increasing the pressure to 10 bar. The pressure had had almost no effect in the case of zeolite $\mathrm{Y}$ where conversion after $50 \mathrm{~h}$ as well as the yield of xylenes remained very similar to atmospheric pressure. This may well be due to the large super cages trapping bulkier $\mathrm{C}_{9} \mathrm{~S}$ and allowing bulkier coke precursors to form. This is further supported with improved conversion and xylenes yield on the addition of Pt, discussed later. Significant improvement in MOR was achieved at pressure as both Beta and MOR showed much reduced deactivation resulting in 37 and 41 wt. $\%$ of conversion after $50 \mathrm{~h}$ TOS 
respectively (Figure 5c). The improvement in MOR could be attributed to reduced pore blockage and coking as the pressure increased and hence access to the large amount of Brønsted acidity yielded much improved transalkylation. The xylenes yield remained the highest over Beta at 25 wt. \% with MOR yielding around 20 wt. \% (Figure 5d).
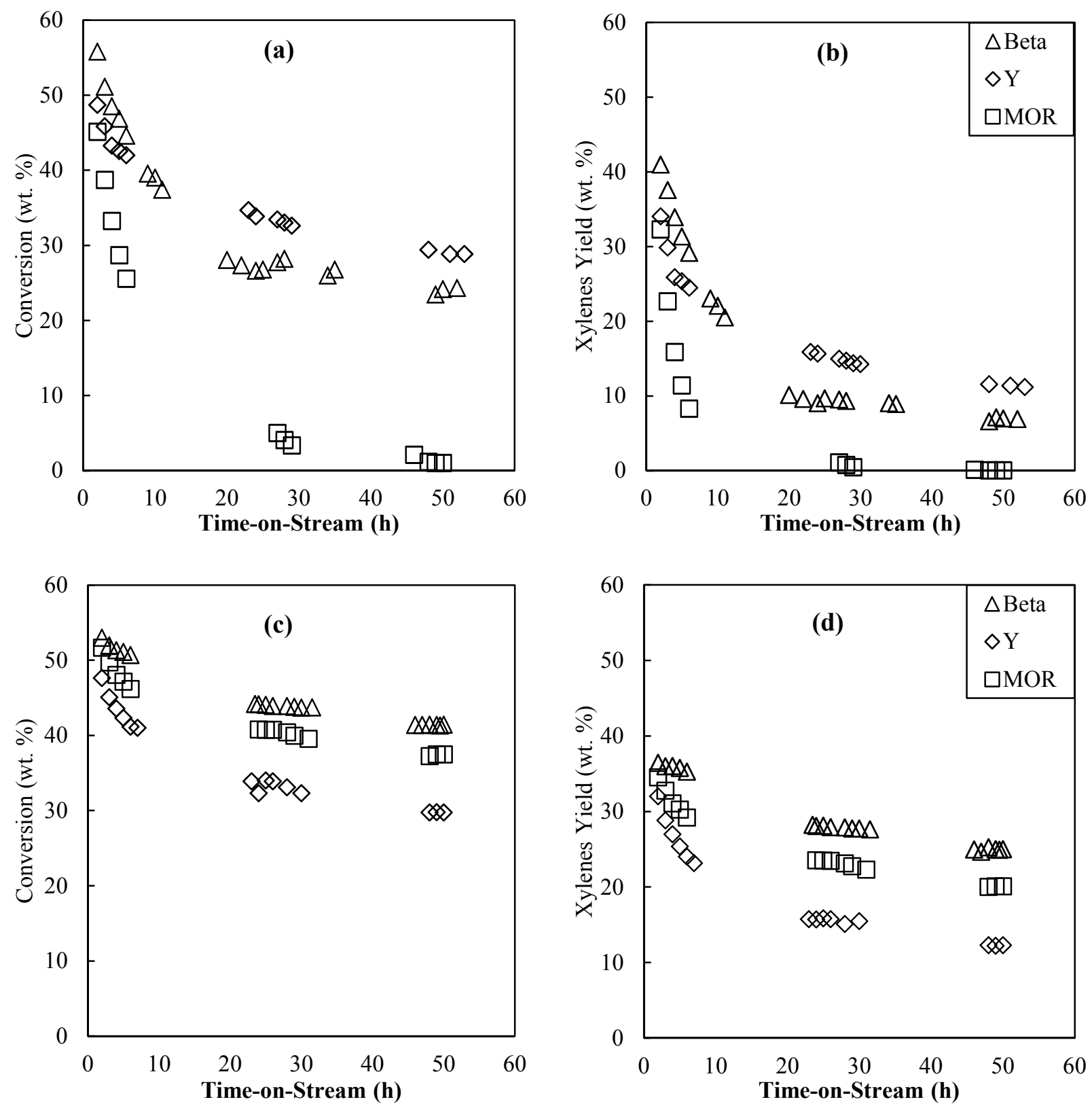

Figure 5: Total feed conversion and xylenes yield over large pore zeolites at 1 bar (a, b) and 10 bar (c, d). 


\subsection{The effect of pressure on the catalytic activity of Pt loaded large pore zeolites}

Although the incorporation of Pt showed no effect on zeolite $\mathrm{Y}$ at atmospheric pressure, all catalysts showed increased conversion as the increase in pressure led to enhanced adsorption of toluene and TMB on the active sites. ${ }^{32}$ The increased pressure also enhanced the hydrogenation of coke precursors with increased occupation of active sites by $\mathrm{H}_{2}$ helping to maintain the activity and lifetime of the bifunctional catalysts (Figure 6). Addition of Pt to MOR enhanced activity at atmospheric pressure but the catalyst steadily deactivated from 55 to 25 wt. \% within $30 \mathrm{~h}$ TOS. However, at higher pressure further reduced fouling/coking led to a significant increase in conversion (56 wt. \%) and improved stability.

Pt addition also further improved conversion over zeolite Beta (6 wt. \% higher at $50 \mathrm{~h}$ TOS), however, at elevated pressure there was a doubling of total feed conversion after $50+\mathrm{h}$ (Figure 6) and an enhancement in both toluene conversion (approximately 400\%) and 1,2,4-TMB conversion (40\%, Table 7). As expected increased activity also resulted in increased light products rising from around $0.2 \mathrm{wt}$ \% for all runs carried out at atmospheric pressure to up to 6 wt. $\%$ of predominantly saturated $\mathrm{C}_{1}-\mathrm{C}_{6} \mathrm{~S}$ were produced at 10 bar with Pt-Beta-800 (Table 7). The highest activity and stability were achieved with Beta but it is worth noting that very similar yields of xylenes were obtained (40 wt. \%) over Beta and MOR with slightly lower at 32 wt. \% over Pt-Y.

The effect of structure can be seen when comparing $\mathrm{C}_{6}-\mathrm{C}_{10}$ aromatic products at elevated $\mathrm{P}$ (Figure 7) with the more open Pt-Y with large alpha cages having approximately $2-5$ times the yield of bulky $\mathrm{C}_{10} \mathrm{~s}$ (TeMBs) than Beta and MOR respectively. The difference between MOR and Beta $\mathrm{C}_{10} \mathrm{~S}$ yield may be done to the increased transalkylation in MOR compared to Beta where the much reduced Brønsted acidity and more balanced $\mathrm{B} / \mathrm{L}$ ratio may give rise to more disproportionation. Although roughly equivalent in B and L acidity in Beta and $\mathrm{Y}$, the higher 
amounts on TMBs observed could well be due to the easier diffusion of the bulkier $\mathrm{C}_{9} \mathrm{~s}$ through Pt-Y. ${ }^{30}$
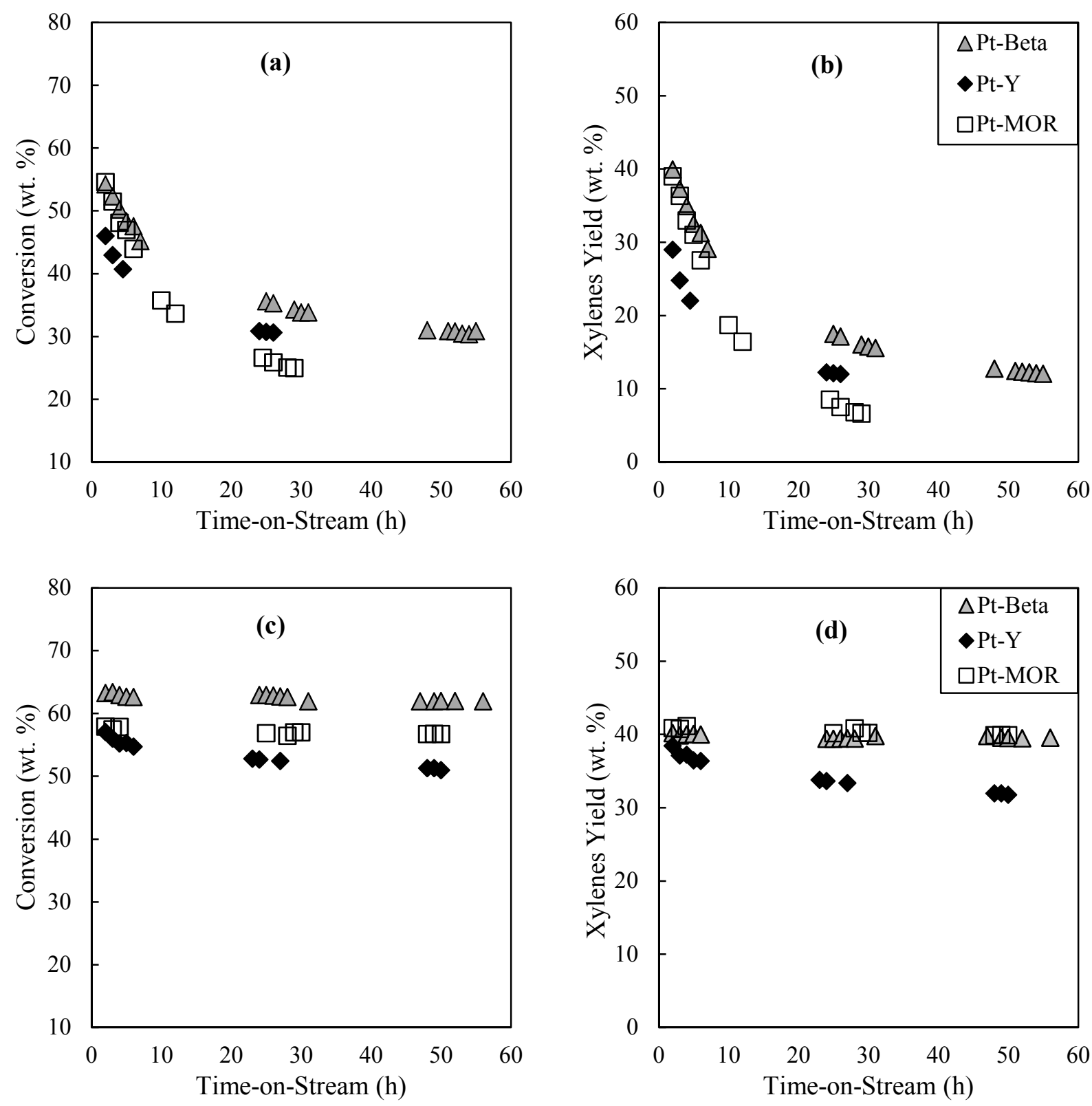

Figure 6: Total feed conversion and xylenes yield over Pt-zeolites (800 ppm) at $P=1$ bar (a,b) and $P=10$ bar (c,d). 

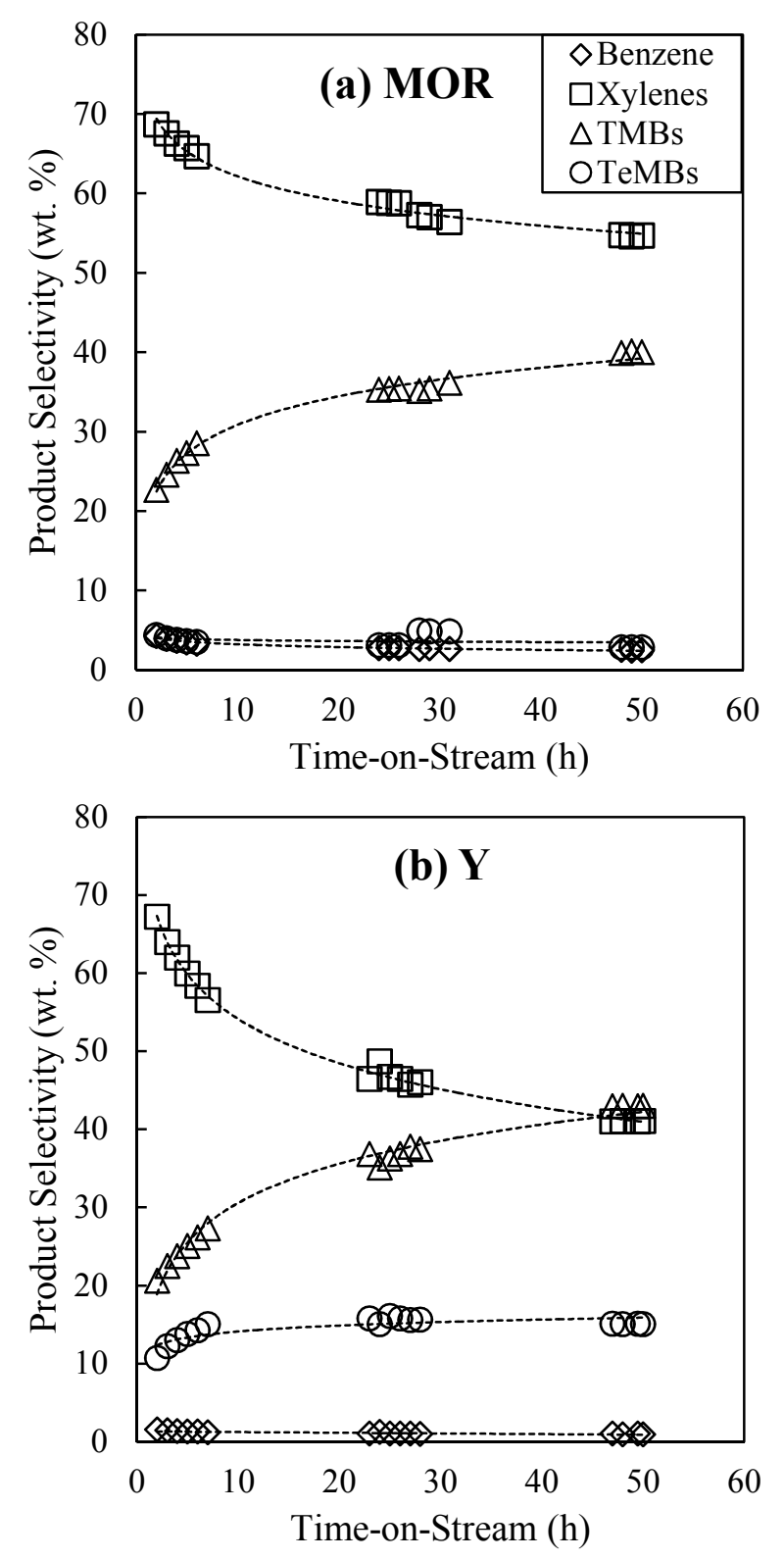

ACS Paragon Plus Environment 


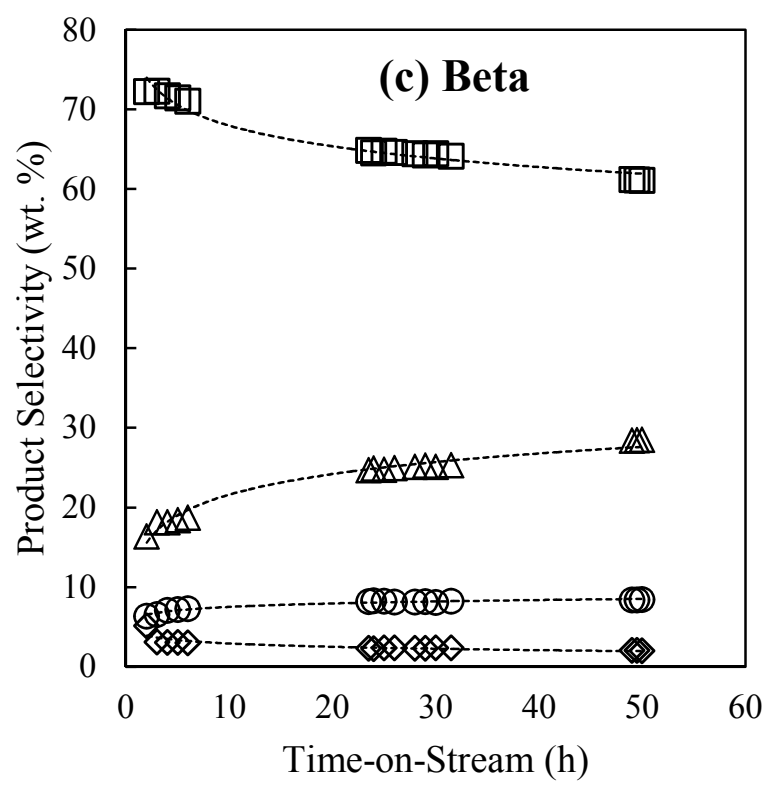

Figure 7: Product selectivity over MOR (a), Y (b), and Beta (c).

\subsection{Effect of reduced Pt loading}

As the amount of $\mathrm{Pt}$ was reduced from $800 \mathrm{ppm}$ on Beta, unsurprisingly the conversion decreased (also see supplementary information). Interestingly though the overall yield of xylenes remained the same for 400 and $800 \mathrm{ppm}$ Pt (Figure 8) for only a small penalty on conversion.
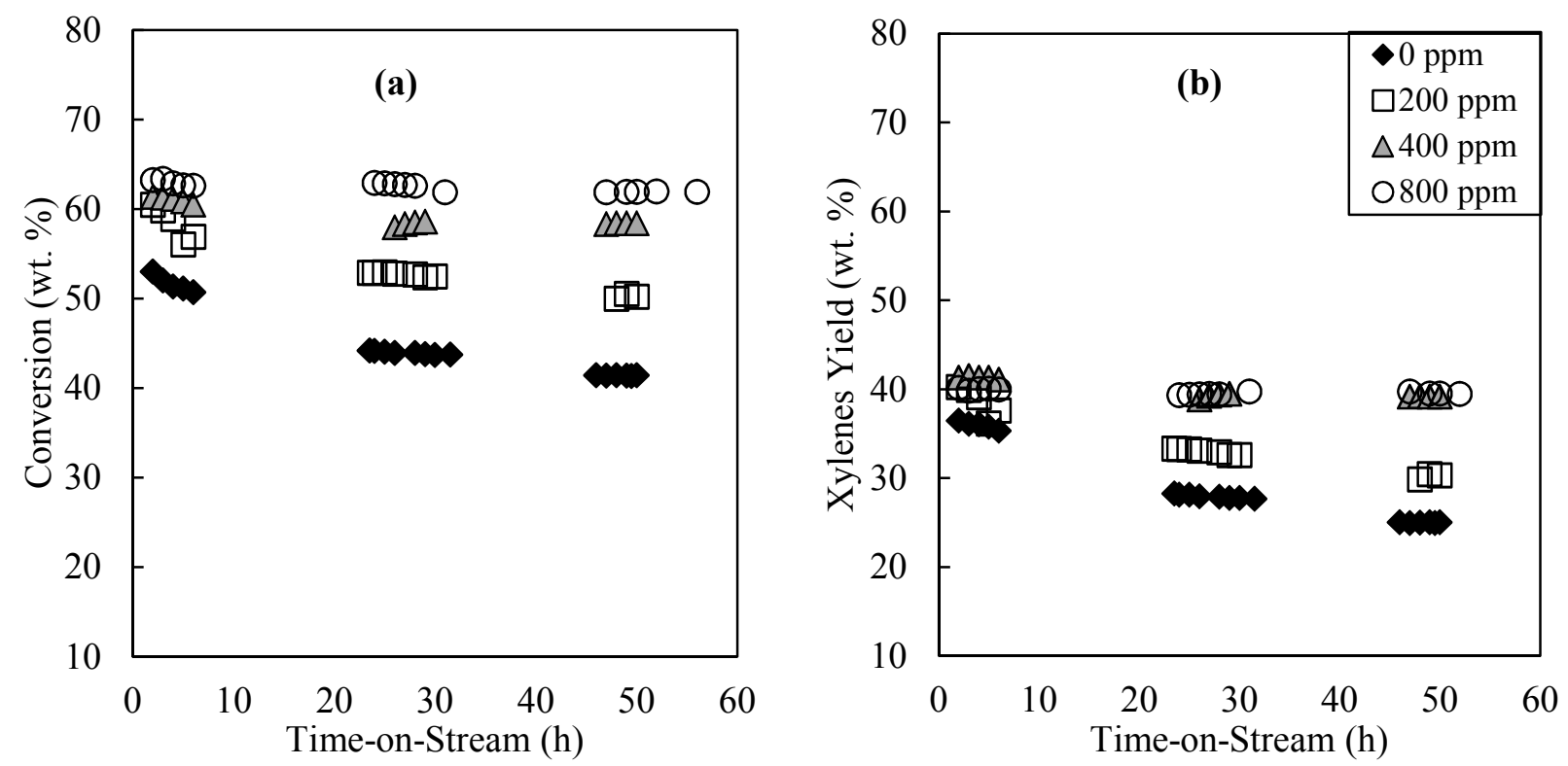

Figure 8: Total feed conversion (a) and xylenes yield (b) at $\mathrm{T}=400{ }^{\circ} \mathrm{C}, \mathrm{P}=10 \mathrm{bar}$ and $\mathrm{WHSV}=5 \mathrm{~h}^{-1}$ over zeolite Beta $(\mathrm{Si} / \mathrm{Al}=12.5)$ with $0,200,400$ and $800 \mathrm{ppm}$ of platinum. 
Halving the Pt content on the other two large pore zeolites showed Y much more sensitive to Pt reduction to $400 \mathrm{ppm}$, with an obvious deterioration in conversion with TOS as the ability to hydrogenate coke precursors was insufficient and the catalyst began to deactivate. Whereas MOR showed good stability with only a decrease of 5 wt. \% in conversion whilst maintaining the yield of xylenes very close to $40 \%$ similar to Beta (Figure 9).
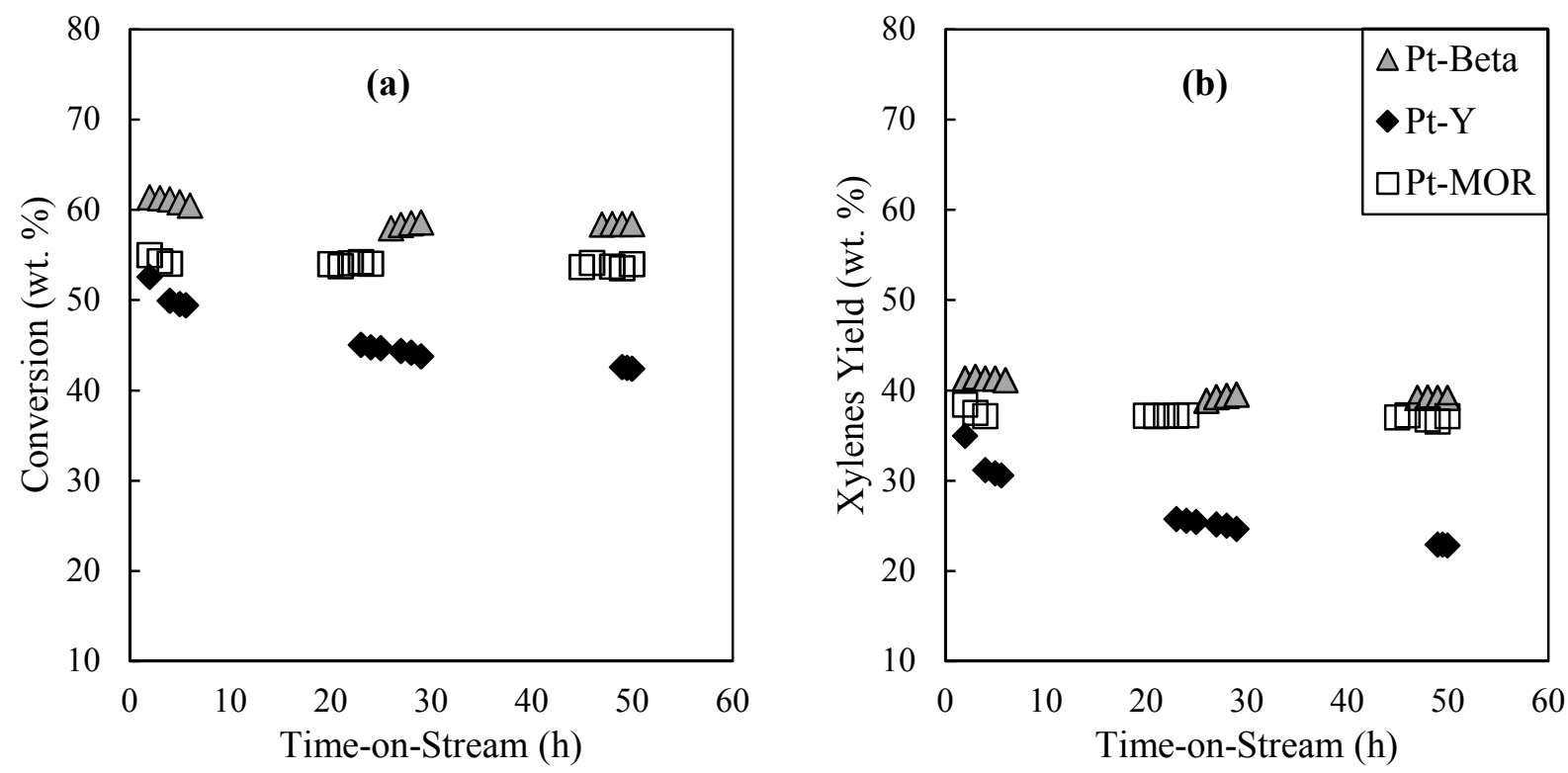

Figure 9: Total feed conversion (a) and xylenes yield (b) over Pt-zeolites (400 ppm) at $\mathrm{P}=10 \mathrm{bar}$.

\subsection{Further consideration of product selectivity over Beta ( 1 and 10 bar)}

\subsubsection{Product Selectivity}

Product selectivity was compared over Pt-Beta-800 (Figure 10) and at 1 bar, xylene production was significantly decreased after $50+\mathrm{h}$, whereas at higher pressure, xylene selectivity remained relatively stable with time on stream around 64 wt. \%. At ambient pressure, TMB isomers (1,3,5- and 1,2,3- ) increased with time resulting in $51 \mathrm{wt} . \%$ compared to only 16 wt. \% at the higher pressure. The TeMBs (1,2,3,4-, 1,2,3,5-, and 1,2,4,5-) were similar at around 8 wt. $\%$ suggesting that the disproportionation reaction of $1,2,4-\mathrm{TMB}$ was limited. Benzene showed 
initial selectivity of $\sim 2.5$ wt. $\%$ at 1 and 10 bar decreasing to 0.9 and 1.8 wt. $\%$ respectively. The increase in benzene suggested that at pressure, the disproportionation of toluene to produce benzene and xylene was favoured rather than the TMB disproportion to produce xylene and TeMBs.
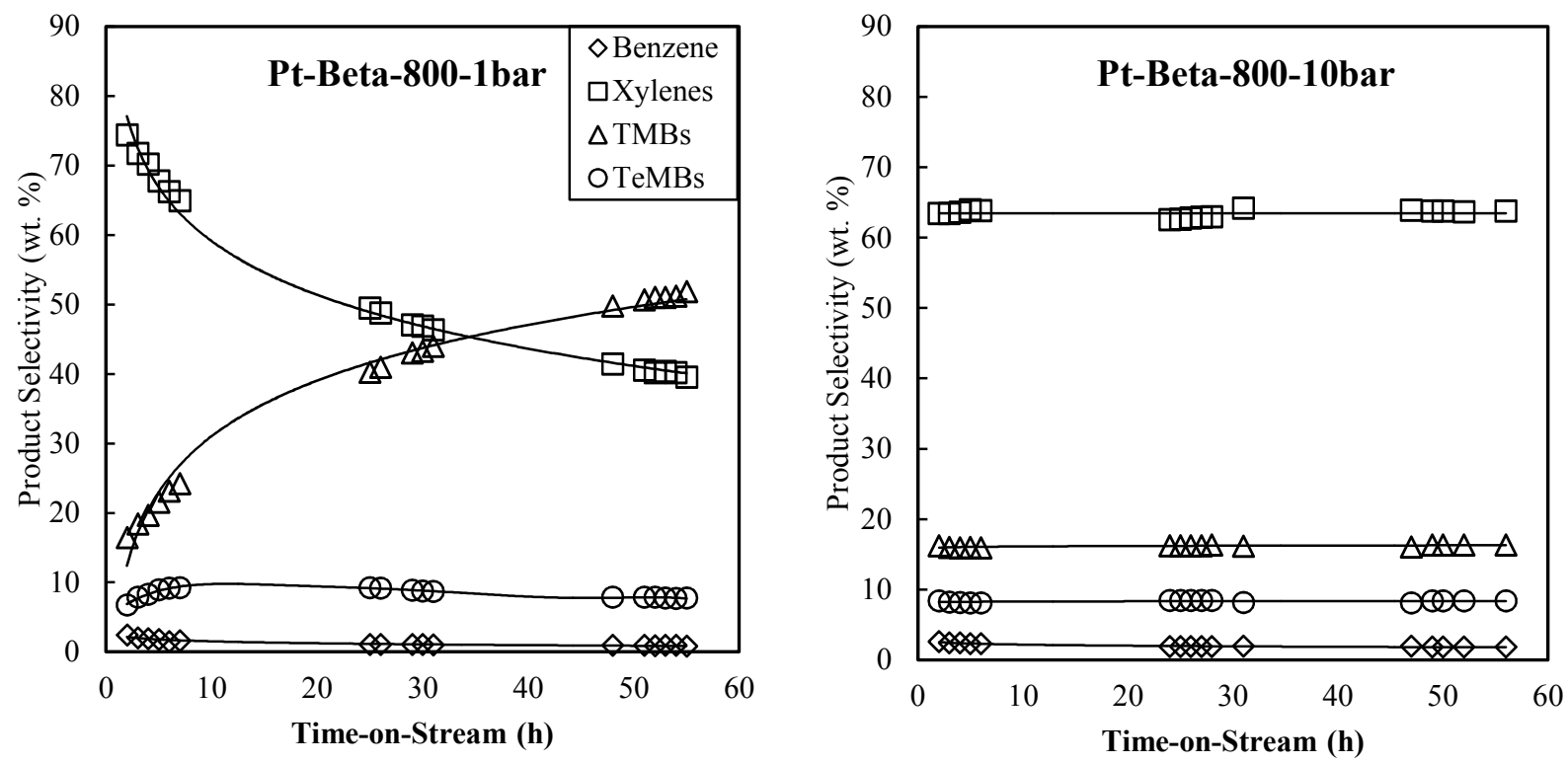

Figure 10: Product selectivity over Pt-Beta-800 at 1 and 10 bar.

\subsubsection{Para-Xylene (p-Xylene) selectivity}

The typical thermodynamic equilibrium values for the distribution of xylene mixtures are $\left(24 \% p-, 52-\% m-\text {, and } 24 \% o_{-}\right)^{30}$ and the experimental p-xylene selectivity at elevated pressure falls within this range (Figure 11b). However, the selectivity to p-xylene was increased above the thermodynamic equilibrium value as the conversion dropped at 1 bar (Figure 11a). The enhancement of p-xylene selectivity could be attributed to increased diffusion limitation (e.g. shape selectivity) which would be exacerbated by the increased coke formation. 

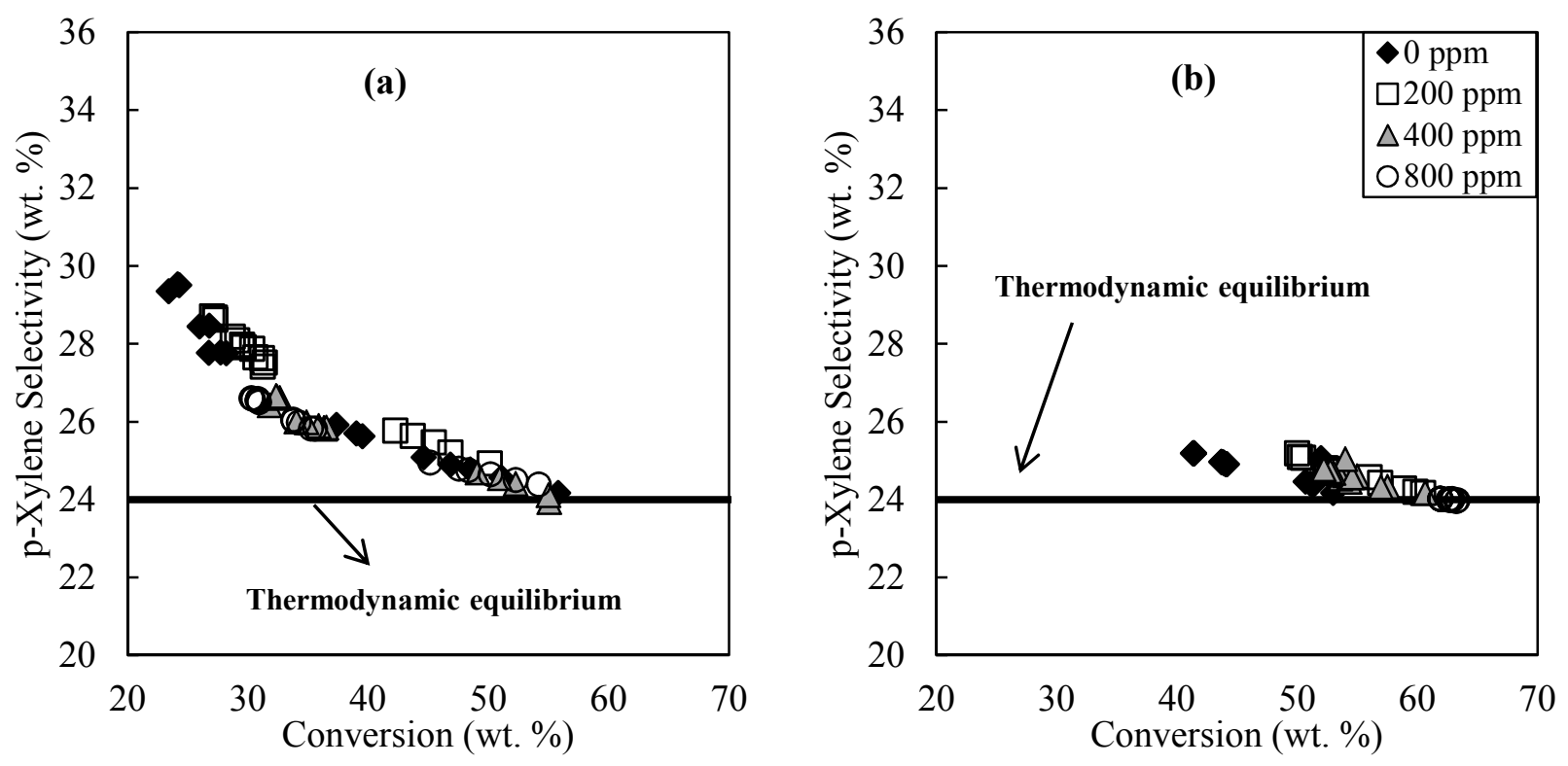

Figure 11: Selectivity to p-Xylene at 1 bar (a) and 10 bar (b) over zeolite Beta $(\mathrm{Si} / \mathrm{Al}=12.5)$ with 0, 200,400 and $800 \mathrm{ppm}$ of platinum.

\subsubsection{Efficiency of xylenes production}

The efficiency of xylenes production was estimated (equations 2 and 3) for the feed of 1,2,4TMB and toluene, with the assumption that one mole of toluene (which is in excess in this reaction) reacted with one mole of $1,2,4-\mathrm{TMB}$ to produce two moles of xylenes ${ }^{31}$. In addition, the selectivity of isomerization (1,3,5-TMB and 1,2,3-TMB) was calculated using equation 4.

$$
\begin{aligned}
& \mathrm{E}(\text { toluene })=\frac{0.5(\text { xylenes wt. } \%)_{\text {product }} / 106}{(\text { toluene wt. } \% \text { Feed }- \text { toluene wt. } \% \text { product }) / 92} \times 100 \\
& \mathrm{E}(\mathrm{TMB})=\frac{0.5(\text { xylenes wt. } \%)_{\text {product }} / 106}{\left(1,2,4 \mathrm{TMB} \text { wt. } \%_{\text {Feed }}-1,2,4 \mathrm{TMB} \text { wt. } \% \text { product }\right) / 120} \times 100 \\
& \mathrm{~S}_{\text {iso }}=\frac{1,3,5 \mathrm{TMB} \text { wt. } \%+1,2,3 \mathrm{TMB} \text { wt. } \%}{(1,3,5 \mathrm{TMB} w \mathrm{wt} \%+1,2,3 \mathrm{TMB} w \mathrm{w} . \%+1,2,4 \mathrm{TMB} w \mathrm{t} . \%)} \times 100
\end{aligned}
$$

The TMB and toluene efficiency levels to produce xylenes as a function of time-on-stream are shown in Figure 12 (a \& b). At 1 bar, these levels were at a maximum at very early time-on- 
stream $(2 \mathrm{~h})$ but then decreased gradually for toluene and significantly for TMB as the catalyst deactivated. However, at elevated pressure, the TMB remained relatively stable at $70 \%$ and although decreased overall, the toluene efficiency level was stable at $56 \%$. Undesirable isomerization of TMBs, leading to bulkier 1,2,3 and 1,3,5 isomers and deactivation, did not increase as the catalyst remained active whereas the selectivity increased to $70 \%$ at ambient pressure mirroring the decline in xylene production from TMB (Figure 12a \& c).
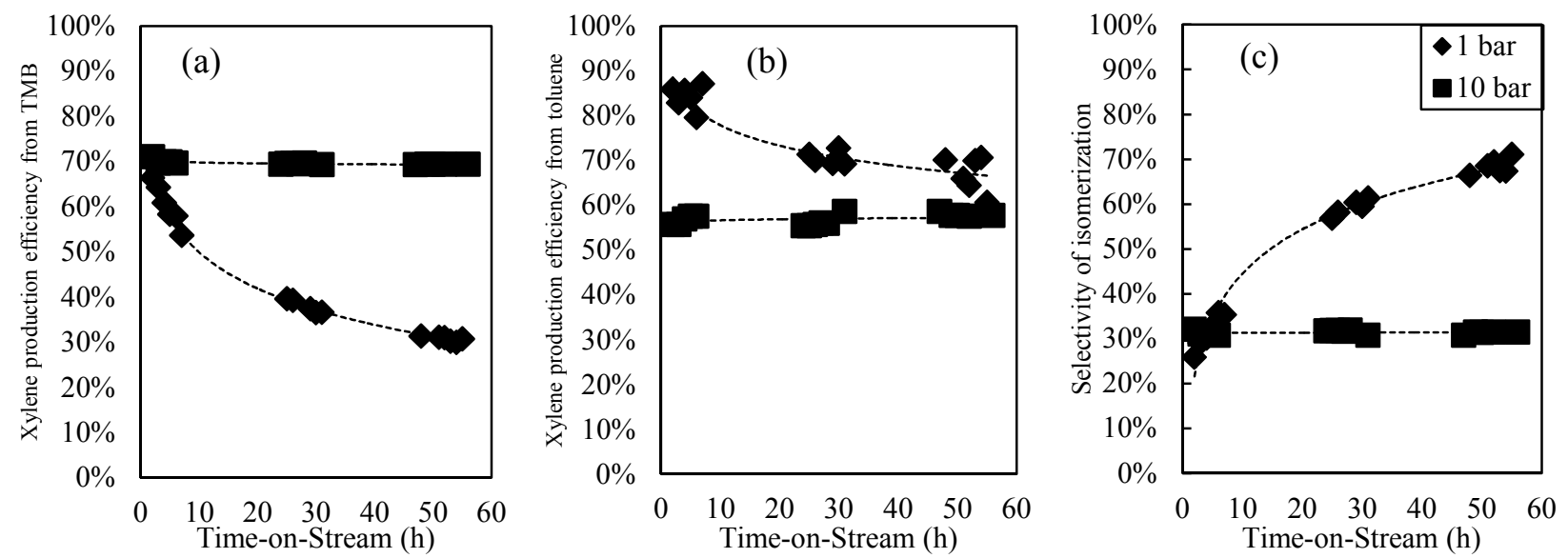

Figure 12: Effect of pressure on xylenes production efficiency from toluene (a) and 1,2,4-TMB (b), and the selectivity to isomerization (c) over Pt-Beta-800 at $\mathrm{T}=400{ }^{\circ} \mathrm{C}$ and $\mathrm{WHSV}=5 \mathrm{~h}^{-1}$.

Table 7: Product distribution over zeolite Beta in the transalkylation of toluene with 1,2,4-TMB at 1:1 w/w, TOS = 50 h $\left(\mathrm{T}=400{ }^{\circ} \mathrm{C}\right.$, WHSV $\left.5.0 \mathrm{~h}^{-1}, \mathrm{H} 2 / \mathrm{HC}=4.0\right)$.

\begin{tabular}{|c|c|c|c|c|c|c|}
\hline $\begin{array}{c}\text { Pt loading (ppm) } \\
\text { P (bar) }\end{array}$ & $\begin{array}{l}0 \\
1 \\
\end{array}$ & $\begin{array}{c}200 \\
1 \\
\end{array}$ & $\begin{array}{c}400 \\
1 \\
\end{array}$ & $\begin{array}{c}800 \\
1 \\
\end{array}$ & $\begin{array}{c}400 \\
10 \\
\end{array}$ & $\begin{array}{c}800 \\
10 \\
\end{array}$ \\
\hline \multicolumn{7}{|l|}{ Conversion (wt. \%) } \\
\hline $1,2,4-\mathrm{TMB}$ & 40.12 & 47.59 & 46.18 & 45.58 & 65.44 & 64.11 \\
\hline Toluene & 9.12 & 6.33 & 16.75 & 16.28 & 51.05 & 59.74 \\
\hline \multicolumn{7}{|l|}{ Product distribution (wt. \%) } \\
\hline Light products $\left(\mathrm{C}_{1}-\mathrm{C}_{6}\right)$ & 0.16 & 0.16 & 0.10 & 0.19 & 3.43 & 6.02 \\
\hline Benzene & 0.19 & 0.19 & 0.23 & 0.28 & 1.15 & 1.12 \\
\hline Toluene & 47.58 & 48.39 & 40.82 & 42.08 & 24.00 & 20.02 \\
\hline p-xylene & 2.06 & 2.72 & 3.42 & 3.30 & 9.45 & 9.49 \\
\hline m-xylene & 3.26 & 4.42 & 6.37 & 6.30 & 20.68 & 20.91 \\
\hline o-xylene & 1.65 & 2.29 & 3.02 & 2.83 & 9.01 & 9.11 \\
\hline Total xylenes & 6.97 & 9.44 & 12.81 & 12.43 & 39.13 & 39.50 \\
\hline $1,3,5-\mathrm{TMB}$ & 11.71 & 11.02 & 11.62 & 11.78 & 7.33 & 7.51 \\
\hline $1,2,4-\mathrm{TMB}$ & 28.25 & 25.34 & 27.43 & 27.07 & 17.62 & 18.05 \\
\hline 1,2,3-TMB & 3.86 & 3.43 & 3.96 & 3.75 & 2.54 & 2.60 \\
\hline
\end{tabular}




\begin{tabular}{lrrrrrr}
$\mathrm{TeMBs}$ & 1.28 & 2.04 & 3.04 & 2.41 & 4.81 & 5.18 \\
$\mathbf{C}_{\mathbf{8}} / \mathbf{C}_{\mathbf{6}}(\mathbf{w t} / \mathbf{w t})$ & 36.09 & 50.27 & 55.94 & 43.76 & 34.12 & 35.17 \\
Xylene isomers (\%) & & & & & & \\
p- & 29.53 & 28.85 & 26.70 & 26.55 & 24.14 & 24.02 \\
$\mathrm{~m}-$ & 46.86 & 46.86 & 49.70 & 50.67 & 52.84 & 52.93 \\
o- & 23.61 & 24.29 & 23.60 & 22.78 & 23.02 & 23.05 \\
Coke wt. \% & $9.49 \pm 0.2$ & $6.82 \pm 0.1$ & $6.13 \pm 0.2$ & $6.09 \pm 0.2$ & $5.25 \pm 0.2$ & $4.55 \pm 0.2$ \\
\hline
\end{tabular}

\section{Conclusions}

The catalytic performance of both $\mathrm{H}$-form and Pt-loaded zeolites: Beta, MOR, and Y were investigated and their conversion and xylenes yield were highest at increased reaction pressure with low levels of Pt impregnation. The effect of pressure enhanced the adsorption of toluene and TMB on the active sites increasing the performance of all catalysts with significant improvement shown by MOR as the hydrogenation of coke precursors prevented the blockage of the unidimensional 12 ring pore structure. The overall activity of all catalysts was similar with the order of activity being Beta $>$ MOR $>$ Y. The addition of Pt enhanced further the conversion and stability, however, the increased hydrogenation of aromatics yielded more light saturated products. Although the highest conversion was observed with 0.08 wt. \% Pt Beta (62 wt.\%), activities were within $10 \mathrm{wt} . \%$ in the order Beta $>$ MOR $>\mathrm{Y}$ with Beta and MOR yielding similar levels of xylenes (40 wt.\%). The more open zeolite Y produced less xylenes (32 wt.\%) and was more sensitive to reduced metal loading as higher levels of isomerization generated bulkier aromatics and disproportionation yielded higher levels of TeMBs in the order Y $>$ Beta $>$ MOR.

The level of metal loading was optimised with the aim of reducing catalyst costs whilst maintaining the desired stability and highest xylenes yield (Figure 13). Lowering the Pt loading to 0.04 wt. \% demonstrated that both Beta and MOR gave very similar xylenes yield for only a 
slight drop in overall activity of MOR. This work is being extended to investigate the effect of alumina binder on activity and selectivity and with a blended C9/C10 feed.
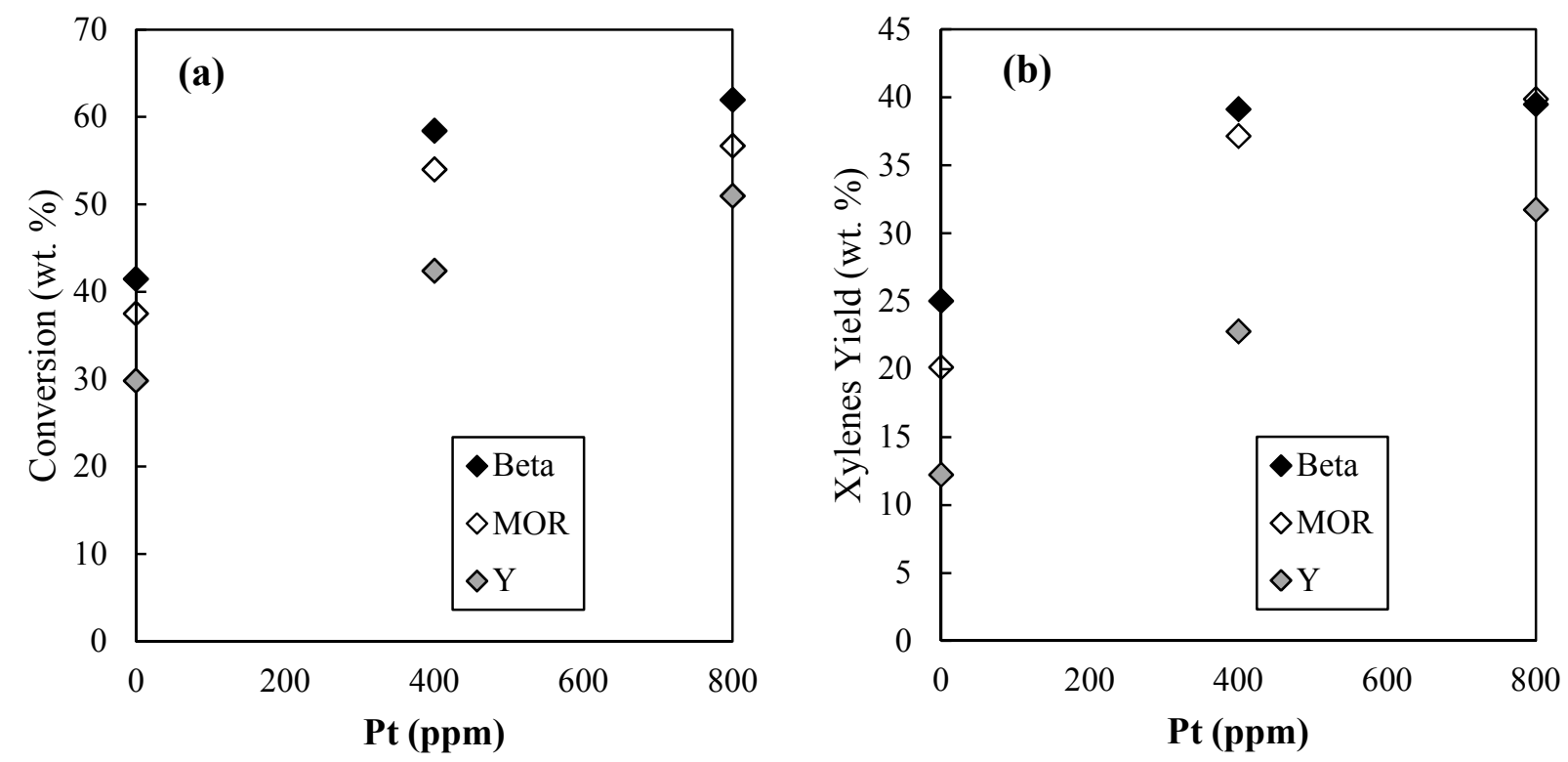

Figure 13: Total feed conversion (a) and xylenes yield (b) at $\mathrm{TOS}=\mathbf{5 0 h}$ vs the Pt loading.

\section{AUTHOR INFORMATION}

\section{Corresponding Author}

arthur.garforth@manchester.ac.uk

School of Chemical Engineering and Analytical Science

The Mill, Sackville Street

Manchester M13 9PL

0044 (0) 1613068850

\section{Author Contributions}

The manuscript was written through contributions of all authors. All authors have given approval to the final version of the manuscript. The main contributors are Faisal Almulla and Arthur Garforth with specific analysis on metal surface area using CO by Dr Sarayute Chansai, PyFTIR by Dr. Vladimir Zholobenko and SEM/TEM by Dr. Patrick Hill. 


\section{Acknowledgements}

The authors would like to acknowledge the financial support from Saudi Aramco. In addition, we wish to recognise the contributions of Dr. John Waters (BET analysis in the School of Earth and Environmental Sciences) and finally Mr. Loris Doyle (for general laboratory technical support in CEAS).

\section{Supporting Information}

- Catalytic activity of different zeolite structures

- Pyridine adsorption studies on catalysts used (Py-FTIR)

- Product distribution change with catalyst

- $\mathrm{p}$-Xylene to o-Xylene $(\mathrm{P} / \mathrm{O})$ ratio vs conversion

- Effect of temperature over the large pore zeolites

- Surface area change with Pt loading

- Studies at atmospheric pressure over Pt-Beta catalysts

\section{References}

1) Feng, P. Aromatics Overview. In: PEMEX petrochemicals forum. Mexico City: IHS Aromatics Overview, 2013.

2) Myers, R. The 100 most important chemical compounds. 1st ed. Westport, Conn.: Greenwood Press, 2007, 36-39.

3) Chang, C., Shihabi, S. Catalyst and process for the selective production of paradialkyl substituted benzenes. 1993, US Patent 5,243,117.

4) Seshan, K. Mobil selective toluene disproportionation process. Appl. Catal., 1990, 58, N13.

5) Ernst, S. Advances in nanoporous materials. 1st ed. Amsterdam: Elsevier Science, 2009, 97-147. 
6) Toda, J., Corma, A., Sastre, G. Diffusion of trimethylbenzenes and xylenes in zeolites with 12-and 10-Ring channels as catalyst for toluene-trimethylbenzene transalkylation. J. Phys. Chem. C, 2016, 120, 16668-16680.

7) Rase, H. Handbook of commercial catalysts. 1st ed. Boca Raton, Fla.: CRC Press, 2000, 29-38.

8) Han, S. Shihabi, D.S. Absil, R.P.L. Huang, Y.Y. Leiby, S.M. Morler, D.O. McWilliams, J.P. ZSM-5 Catalyst developed for toluene disproportionation. Oil Gas J., 1989, 21, 83-87.

9) Perego, C., A. Carati. Zeolites and zeolite-like materials in industrial catalysis. Zeolites, 2008, 357-389.

10) Röger, H., Möller, K., O'Connor, C. The transformation of 1,2,4-trimethylbenzene A probe reaction to monitor external surface modifications of HZSM-5?. Microporous Mater., 1997, 8, 151-157.

11) Park, S., Lee, J., Rhee, H. Disproportionation of 1,2,4-trimethylbenzene over zeolite NU-87. Korean J. Chem. Eng., 2000, 17, 198-204.

12) Park, S., Rhee, H. Shape selective conversion of 1,2,4-trimethylbenzene over zeolite NU-87. Catal. Today, 2000, 63, 267-273.

13) Dumitriu, E., Hulea, V., Kaliaguine, S., Huang, M. Transalkylation of the alkylaromatic hydrocarbons in the presence of ultrastable Y zeolites transalkylation of toluene with trimethylbenzenes. Appl. Catal., A, 1996, 135, 57-81.

14) Čejka, J., Kotrla, J., Krejčí, A. Disproportionation of trimethyl benzenes over large pore zeolites: catalytic and adsorption study. Appl. Catal., A, 2004, 277, 191-199. 
15) Aitani, A., Ali, A., Waziri, S., Al-Khattaf, S. Production of xylenes from toluene and 1,2,4-trimethylbenzene over ZSM-5 and mordenite catalysts in a fluidized-bed reactor. Chem. Eng. Technol., 2010, 33, 1193-1202.

16) Hulea, V., Bilba, N., Lupascu, M., Dumitriu, E., Nibou, D., Lebaili, S., Kessler, H. Study of the transalkylation of aromatic hydrocarbons over SAPO-5 catalysts. Microporous Mater., 1997, 8, 201-206.

17) Tsai, T., Chen, W., Liu, S., Tsai, C., Wang, I. Metal zeolites for transalkylation of toluene and heavy aromatics. Catal. Today, 2002, 73, 39-47.

18) Zaiku, X., Jiaqing, B., Yiqing, Y., Qingling, C., Chengfang, Z. Effect of treatment with $\mathrm{NaAlO}_{2}$ solution on the surface acid properties of zeolite $\beta$. J. Catal., 2002, 205, $58-66$.

19) Matsuda, T., Asanuma, M., Kikuchi, E. Effect of high-temperature treatment on the activity of montmorillonite pillared by alumina in the conversion of $1,2,4-$ trimethylbenzene. Appl. Catal., 1988, 38, 289-299.

20) Li, Y., Wang, H., Dong, M., Li, J., Qin, Z., Wang, J., Fan, W. Effect of zeolite pore structure on the diffusion and catalytic behaviors in the transalkylation of toluene with 1, 2, 4-trimethylbenzene. RSC Adv, 2015, 5, 66301-66310.

21) Tsai, T., Liu, S., Wang, I. Metal supported zeolite for heavy aromatics transalkylation process. Catal. Surv. Asia, 2009, 13, 94-103.

22) Krejčí, A., Al-Khattaf, S., Ali, M., Bejblová, M., Čejka, J. Transalkylation of toluene with trimethylbenzenes over large-pore zeolites. Appl. Catal., A, 2010, 377, 99-106. 
23) Meshram, N., Kulkarni, S., Ratnasamy, P. Transalkylation of toluene with C9 aromatic hydrocarbons over ZSM5 zeolites. J. Chem. Technol. Biotechnol., Chem. Technol., 1984, 34, 119-126.

24) Szakács, S., Papp, J., Lejtovicz, D., Kalló, D. Transmethylation of trimethylbenzenes and toluene on H- and Ni/H-mordenites. React. Kinet. Catal. Lett., 1982, 21, 365-370.

25) $\mathrm{Wu}$, J., Leu, L. Toluene disproportionation and transalkylation reaction over mordenite zeolite catalysts. Appl. Catal., 1983, 7, 283-294.

26) Chao, P., Lin, H., Chen, C., Wang, P., Chen, Y., Sei, H., Tsai, T. Precoking selectivation for improving benzene product purity in heavy aromatics transalkylation. Appl. Catal., A, 2008, 335, 15-19.

27) Ali, S., Aitani, A., Ercan, C., Wang, Y., Al-Khattaf, S. Conversion of heavy reformate into xylenes over mordenite-based catalysts. Chem. Eng. Res. Des., 2011, $89,2125-2135$.

28) Drews, A. Manual on hydrocarbon analysis. 1st ed. West Conshohocken, PA: ASTM, 1998, 234-237.

29) Al-Khattaf, S., Ali, S., Aitani, A., Al-Nawad, K., Chiu, C., Tsai, T. Catalysis of metal supported zeolites for dealkylation-transalkylation of alkyl-aromatics. Appl. Catal., A, 2016, 514, 154-163.

30) Al-Khattaf, S. Effect of Y-zeolite acidity on reactions of 1,2,4-trimethylbenzene. Energy Fuels, 2007, 21, 646-652.

31) Dumitriu, E., Guimon, C., Hulea, V., Lutic, D., Fechete, I. Transalkylation of toluene with trimethylbenzenes catalyzed by various AFI catalysts. Appl. Catal., A, 2002, 237, 211-221. 
32) Wang, I., Tsai, T., Huang, S. Disproportionation of toluene and of trimethylbenzene and their transalkylation over zeolite beta. Ind. Eng. Chem. Res., 1990, 29, 20052012. 